\title{
PREVENTION OF RECURRENCES OF RHEUMATIC FEVER
}

BY

\section{E. G. L. BYWATERS, M.B., F.R.C.P. KATHERINE HALLIDIE-SMITH, M.R.C.S. D.C.H.}

\author{
AND
}

\section{G. T. THOMAS, M.B., M.R.C.P. \\ From the Special Unit for Juvenile Rheumatism, Canadian Red Cross Memorial Hospital, Taplow, Maidenhead,} Berkshire

Each attack and every recurrence of rheumatic fever is preceded by infection of the throat with group A betahaemolytic streptococci. If this infection could be prevented or eliminated by early treatment, rheumatic fever and rheumatic heart disease would be exterminated. This is now almost universally accepted. It is, however, not feasible to prevent all group A betahaemolytic streptococcal infections in the general population, and, while it is theoretically possible to eliminate such infection in the individual by early treatment, this is difficult in practice in more than a small proportion of patients. A more limited objective is the prevention of rheumatic fever recurrences.

\section{Prophylaxis of Proved Value}

It is 18 years since sulphonamides were first used for the prevention of rheumatic fever recurrences by Thomas and France (1939) and Thomas et al. (1941), and almost simultaneously by Coburn and Moore (1940). All subsequent studies and all those conducted using penicillin in a similar way have confirmed the value of these measures (Houser and Eckhardt, 1952; Bywaters, 1952, 1954). Experts agree on their value (Mortimer and Rammelkamp, 1956), and on the amount of invalidity and suffering that could be avoided were these measures used throughout the world. Experienced observers hold that "the extent of cardiac damage appears to increase with the number of recurrences" (Wilson, 1940), and " the degree of disability and the ultimate longevity of those with injured hearts are largely influenced by the frequency, duration, and severity of recurrences" (Bland and Jones, 1952).

Yet in this country it is an exception to find children or adults who have recently had rheumatic fever protected in this way against further attacks. Apart from some paediatric teaching centres, few of the teaching hospitals and fewer of the non-teaching hospitals use this measure. It is true that only a small number of rheumatic fever cases are now admitted, compared with, say, 50 years ago, yet in notifying areas $0.027 \%$ of schoolchildren are attacked by rheumatic fever each year (Leff, 1956) (taking the mean of the last three years, 1951-3, for all areas). If this rate applies to all the children of England and Wales, we can calculate that each year about 2,000 children develop rheumatic fever and need protection for an average period of five years. It becomes important, therefore, to find out why this well-established prophylactic measure is not being used in this country either by consultants in the hospitals or by general practitioners in the home. Some of the reasons have been uncovered by a review of our own prophylactic scheme and the extent to which it has been implemented when the patient returns home.

\section{Why Prophylaxis is Abandoned}

Prophylaxis has been undertaken in this unit since 1951, using either sulphadiazine or triple sulphonamide 0.5 g. b.d. or penicillin $G 200,000$ units b.d. All patients with proved or probable rheumatic fever or chorea since then have been discharged from hospital on this regime. They are given a supply to last three months and a letter is sent to the family doctor suggesting that this should be continued until the age of 20. The patients are seen at 6- or 12-month intervals at our own follow-up clinics. Erythrocyte sedimentation rate and antistreptolysin $O$ titre are measured and urine tests for sulphonamide made at each attendance. Results of such follow-up examinations and recommendations are incorporated in letters to the family doctor and school medical officer. Sulphonamide is dispensed in the clinics in amounts to last six months. If the patient has finished the supply before his next visit, he may either write in for more or obtain them from his own doctor. Penicillin is given by prescription for three months at the follow-up clinics or is supplied by the family doctor; patients may write directly to the hospital for further supplies.

By inquiry of patients, parents, and doctors we have found that most parents co-operate to a variable extent, depending upon their conscientiousness, ability to control their children, their comprehension of the measure, and their trust in the doctor: others are apathetic, and still others appear to be confused by the difference between their own doctor's instructions and those of the hospital doctor. Many doctors approve of the scheme and co-operate well, but others are apathetic, and others oppose this measure.

The difficulties we have encountered may be summarized as follows:-(1) Parental : (i) apathy, (ii) lack of supervision. (2) General practitioner opposition on account of: (i) swelling the drug bill, (ii) making children hypochondriacs, (iii) lack of knowledge of its value, (iv) fear of toxic reactions, (v) fear of bacterial resistance developing, (vi) fear of penicillin loss of potency over three-month periods and subsequent too frequent (monthly) prescribing, and (vii) the fact that the disease is now uncommon and diminishing.

\section{Medical Opposition Examined}

It must be admitted that most of these reasons for medical opposition have some element of validity in them, but the measures advocated have been tested out practically and successfully over a prolonged period of time. For reasons often stated before, we consider, in common with the American Heart Association (1953), recently reviewed in this Journal, that the advantages greatly outweigh the possible disadvantages. To take the medical objections serially:

1. Cost per day (based on hospital costs).

\begin{tabular}{|c|c|}
\hline $\begin{array}{l}\text { nicillin } G^{*} \\
\text { lpenicillin (penicillin V) } \\
\text { ämide (“ sulphatriad ") } \\
\text { ("gantrisin") }\end{array}$ & $\begin{array}{l}\text { Dosage } \\
200,000 \text { units b.d. } \\
120 \text { mg. b.d. } \\
0.5 \text { g. b.d. } \\
0.5 \text { g. b.d. } \\
0.5 \text { g. b.d. }\end{array}$ \\
\hline
\end{tabular}

This seems a small price to pay for protection against a second attack of rheumatic fever and possible further cardiac damage.

2. Hypochondriacs are made, not by pills but by parental attitudes."

3. Failure to realize the value of prophylaxis is widespread and bears no relation to the excellence or otherwise of the physician in general.

4. Toxic reactions are rare with sulpha drugs, and if they occur they usually do so within the first three months of prophylaxis-i.e., with our own patients usually while they are still convalescent under observation in hospital. In a five-year period with about 500 patients discharged on prophylaxis-mostly a sulphonamide but some on penicillin-we have had only one serious (but not fatal) reaction, a patient developing agranulocytosis after sulphadiazine for eight weeks. Others have shown transient leucopenia ( 2 cases) or urticarial rash of doubtful aetiology. Renal damage will not occur in this dosage and with these drugs. Rarely, reactions have occurred with therapeutic dosage, after a prior period on prophylactic dosage. Penic1llin sensitivity (mainly skin reaction) is rare on prophylactic

*Benzathine penicillin is only long-acting intramuscularly, and offers no commensurate advantage for its extra cost by mouth. 
dosage, and also occurs in the early convalescent period. We have had very few, none severe.

5. Streptococcal resistance to sulphonamides develops only under epidemic conditions, in closed institutions: it is not serious, since change can be made to penicillin, to which streptococci remain sensitive. Staphylococcal resistance to penicillin can be a nuisance, but again emerges in this country usually only under institutional or hospital conditions, not at home. We have had no trouble in this institution over the last five years. If staphylococcal-resistant strains appear, other antibiotics are available.

6. Loss of potency of penicillin tablets may occur on exposure to moist air, but penicillin should last at least three months unimpaired if stored in an air-tight bottle in a cool place. Some brands are packed in metal foil as an additional protection against humidity.

7. This is no reason for not protecting those particularly susceptible.

8. Another objection, more difficult to meet, is that another method of prophylaxis exists-that of treating promptly every sore throat in such patients with bactericidal doses of penicillin. This is useful should a sore throat develop in a rheumatic child because of omission of prophylaxis, but it is not always successful and it is not practical as a general measure, since all group A streptococcal infections are not manifest as sore throats, all children do not complain, all parents do not go to the doctor, and all doctors do not use this method. We consider routine daily prophylaxis safer.

The prevention of first attacks of rheumatic fever in a susceptible population also needs attention but is another and separate problem.

\section{Conclusions}

We conclude that measures should be taken in this country to acquaint physicians in general with the advantages to be gained from routine daily prophylaxis against rheumatic fever relapses. Opportunities exist at meetings of learned societies and in medical publications. Full discussion of possible disadvantages is needed together with accounts of practical experience in this field. Lay education should not be neglected.

\section{REFERENCE}

American Heart Association (1953). Lancet, 1, 285. Bland, E. F., and Jones, T. D. (1952). Ann. intern. Med., 37, 1006 Bywaters, E. G. L. (1952). Brit. med. Bull., 8, 343.

(1954). Courrier, 4, 357

Coburn, A. F., and Moore, L. V. (1940). Med. clin. N. Amer., 24, 633 Houser, H. B., and Eckhardt, G. C. (1952). Ann. intern. Med., 37, 1035. Leff, S. (1956). Ann. rheum. Dis., 15, 33.

Mortimer, E. A., and Rammelkamp, C. H. (1956). Circulation, 14, 1144 Thomas, C. B., and France, R. (1939). Bull. Johns Hopk. Hosp., 64, 67. - and Reichsman, F. (1941). J. Amer. med. Ass., 116, 551 Wilson, May G. (1940). Rheumatic Fever. Commonwealth Fund, New

\section{TERMINOLOGY OF THE HEREDITARY HAEMOGLOBINOPATHIES WITH HAEMOGLOBIN VARIANTS}

\section{By a Working Party* of the Colonial Medical RESEARCH COMMITTEE}

The following recommendations are based on immediate practical requirements rather than on fundamental theoretical considerations, and are put forward at the present time solely with the aim of discouraging the growth of ambiguous systems of terminology until an agreed international system has been devised.

\section{General Recommendations}

(a) The term sickle-cell disease should be used to denote any pathological condition which is, in part, attributable to sickling of the red cells. The term sickle-cell anaemia should be reserved to denote the presumably homozygous state. Its use is (strictly) conditional upon the demonstration of homozygosity from family studies. (b) Foetal haemoglobin is excluded from the present discussion of terminology, though its persistence in varying degree is an often-observed feature of states involving the haemoglobin variants. Statements regarding its occurrence should be made as part of the biochemical findings.

(c) The working party appreciates the desirability of having a complete statement of the haemoglobin variants actually present, preferably in order of decreasing proportions, leaving the clinician to decide if an actual (or potential) pathological situation needs to be described, and the geneticist to state how the observed combination of haemoglobin variants has arisen. The working party also appreciates the undesirability of using a terminology with genetic implications in the absence of family studies.

(d) The term haemoglobinopathy should be used to denote a condition in which the production of normal adult haemoglobin (Hb-A) is partly or wholly suppressed and it is partly or wholly replaced by one or more haemoglobin variants, which may include foetal-type haemoglobin $(\mathrm{Hb}-\mathrm{F})$

\section{Specific Recommendations}

(a) The term sickle-cell should be hyphenated when used as an adjective.

(b) Excluding Hb-F from consideration, the biochemical state involving $\mathrm{Hb}-\mathrm{A}$ and any other one haemoglobin variant ( $\mathrm{Hb}-\mathrm{X}$ ) should be described as $\mathrm{Hb}-\mathrm{X}$ trait.

(c) The term disease and not the term anaemia should be used generally to denote pathological conditions associated with haemoglobin variants.

(d) The term thalassaemia should be retained because the genetic variants of thalassaemia present themselves as such These variants should be described as $\mathrm{Hb}-\mathrm{C} /$ thalassaemia, $H b-E /$ thalassaemia, etc. The term thalassaemia should be used rather than the terms Cooley's anaemia, microcythemia, etc. The qualifying terms major and minor are in practice used to denote the presumably homozygous and heterozygous states respectively, but their use in this way is (strictly) conditional on supporting evidence for the nature of the genotype from family studies.

(e) A morbid condition, not presenting itself as sickle-cell disease or as a variant of thalassaemia, but produced by any one or two $\mathrm{Hb}$ variants, in the absence of $\mathrm{Hb}-\mathrm{A}$, should be described as a disease-e.g., $\mathrm{H} b-\mathrm{C}$ disease, $\mathrm{H} b-\mathrm{C} / \mathrm{H} b-\mathrm{D}$ disease (hypothetical). It is appreciated that some of the possible combinations are not yet known to produce morbidity in adults.

\section{Examples of Known Haemoglobin Combinations}

(Note--In these examples the haemoglobin variants given in parentheses are not always found).

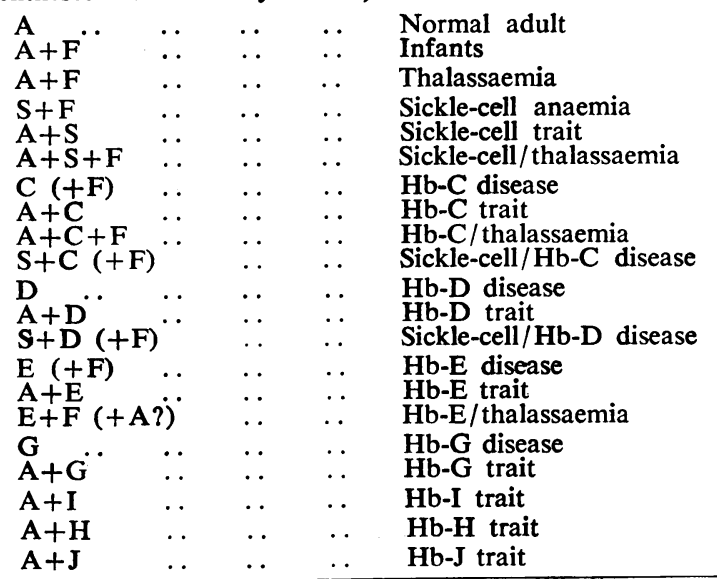

*The Colonial Medical Research Committee's working party on sickle-cell trait and sickle-cell anaemia, which prepared these on sickle-cell trait and sickino-cell anansists of the following: Prorecommendations on terminology, consists of C. Allison, Professor fessor A. W. Woodruff (chairman), Dr. A. C. Allison, Professor fessor B. G. Maegraith, Dr. A. E. Mourant, Dr. A. B. Raper, Dr. J. C. White, Dr. G. H. Beaven (secretary). 